\title{
Preparation of copper-silver alloy with different morphologies by a electrodeposition method in 1-butyl-3-methylimidazolium chloride ionic liquid
}

\author{
SUN JIE, MING TING-YUN* ${ }^{*}$, QIAN HUI-XUAN and LI QI-SONG \\ School of Environmental and Chemical Engineering, Shenyang Ligong University, Shenyang 110159, \\ People's Republic of China \\ *Author for correspondence (1350548424@qq.com)
}

MS received 3 December 2018; accepted 21 May 2019

\begin{abstract}
Electrodeposition of a copper-silver alloy based on a 1-butyl-3-methylimidazolium chloride (BMIC) ionic liquid was studied. The electrochemical behaviour of copper and silver ions was characterized by cyclic voltammogram. The morphologies and phase compositions of copper-silver alloy coating under different electrodeposition conditions were investigated by scanning electron microscopy and X-ray diffraction. The results show that copper-silver alloys with different micro-morphologies can be obtained under different potential conditions in BMIC. Co-deposition of the copper-silver alloy followed a two-step reduction process, the first step is the reduction of the cupric ion to the cuprous ion and the second step is the simultaneous reduction of the cuprous ion and the silver ion to form an alloy. A dendritic alloy can be obtained at $-0.60 \mathrm{~V}$, a bract alloy can be obtained at $-0.80 \mathrm{~V}$ and a granular alloy can be obtained at $-1 \mathrm{~V}$. The coating particle size at $60^{\circ} \mathrm{C}$ was smaller than the particle size obtained at $40^{\circ} \mathrm{C}$. The $\mathrm{Cu}-\mathrm{Ag}$ alloy prepared by electrodeposition in ionic liquids consists of single-phase copper and single-phase silver.
\end{abstract}

Keywords. Ionic liquid; electrodeposition; metals and alloys; copper-silver alloy; morphology; thin films.

\section{Introduction}

In recent years, ionic liquids have been widely used in the fields of water treatment, atmospheric treatment and metal electrodeposition due to their advantages of wide electrochemical window, stable physical and chemical properties and green environmental protection [1,2]. In the field of electrodeposition of metal copper and copper alloys in ionic liquids, researchers have also conducted related studies, such as electrodeposition of a copper-zinc alloy in choline acetate and 1butyl-1-methylpyrrolidinium bis(trifluoromethylsulfonyl) imide [3,4], electrodeposition of an aluminium-zirconiumcopper ternary alloy in triethylamine hydrochloride [5], electrochemical behaviour of the electrodeposition process on a copper-lithium alloy in 1-butyl-3-methylimidazolium tetrafluoroborate ionic liquids [6] and electrochemical behaviour of a copper-manganese alloy in $N$-butyl- $N$ methylpyrrolidinium bis(trifluoromethylsulphonyl) imide ionic liquids [7]. In these studies, many beneficial results have been obtained with regard to the electrochemical behaviour of different copper alloys. In addition, investigations showed that the BMIC ionic liquid was very suitable for the electrodeposition of metals and alloys [8,9].

As copper-silver alloy coating which has important applications in the field of catalysis, there have been few studies on electrodepositing copper-silver alloys in ionic liquids.
Rajagopal et al [10] conducted electrochemical behaviour studies of copper-silver alloy electrodeposition in a triethylammonium acetate ionic liquid. Reyna-González et al [11] studied the electrochemical behaviour and nucleation growth mechanism of copper-silver alloy electrodeposition in 3-butylpyridinium bis(trifluoromethanesulphonyl) imide. From the results of these studies, it can be seen that the morphology of the copper-silver alloy obtained in the fixed electrodeposition system is relatively simple, while the copper-silver alloy is often used as a catalyst, which may limit the application of the alloy plating.

In this paper, electrodeposition of the copper-silver alloy with different micromorphologies has been carried out in a 1-butyl-3-methylimidazolium chloride (BMIC) ionic liquid. The electrochemical behaviour, microstructure and phase composition of the copper-silver alloy were studied by cyclic voltammetry $(\mathrm{CV})$, scanning electron microscopy (SEM) and $\mathrm{X}$-ray diffraction (XRD).

\section{Experimental}

The electrochemical behaviour of the copper chloride and silver nitrate was determined by using a CV curve method based on a BMIC ionic liquid. Electrodeposition of the 
copper-silver alloy under different conditions was carried out on a brass substrate according to the results of $\mathrm{CV}$. All ionic liquids used were $6 \mathrm{~h}$ of vacuum distillation at $60^{\circ} \mathrm{C}$ first, and then vacuum drying for $24 \mathrm{~h}$ at $90^{\circ} \mathrm{C}$. And the copper chloride and silver nitrate metal salts were also vacuum dried for $24 \mathrm{~h}$ at $90^{\circ} \mathrm{C}$ before experiment. In addition, electrodeposition experiments were carried out under the protection of nitrogen gas.

$\mathrm{CV}$ and electrodeposition experiments were performed by a CS350 electrochemical workstation. A conventional threeelectrode cell was used with a graphite electrode as the counter electrode, a silver wire as the reference electrode, a glassy carbon (GC) electrode (CV) and a brass plate (electrodeposition experiments) as the working electrode. Acetone, anhydrous ethanol and deionized water were used to clean all the electrodes before testing. In addition, working electrodes were polished to mirror smoothness by using different types of sandpapers. The morphology and phase composition of coatings were characterized by S-3400 SEM and D/max-RB XRD.

\section{Results}

\subsection{Analysis of redox behaviour of copper ions and silver ions}

Figure 1 shows the $\mathrm{CV}$ of $\mathrm{BMIC}-\mathrm{CuCl}_{2} \cdot 2 \mathrm{H}_{2} \mathrm{O}\left(0.1 \mathrm{moll}^{-1}\right)-$ $\mathrm{AgNO}_{3}\left(0.1 \mathrm{moll}^{-1}\right)$. It can be seen that there exist two peaks labelled as $\mathrm{C} 1$ and $\mathrm{C} 2$ in the part of the reduction curve. $\mathrm{C} 1$ corresponds to the reduction of $\mathrm{Cu}^{2+} / \mathrm{Cu}^{+}$and $\mathrm{C} 2$ is the reduction peak of the co-deposition of the copper-silver alloy [12-14]. This indicates that the reduction of the copper and silver ions is carried out in two steps. The first step is the reduction of the cupric ion $\left(\mathrm{Cu}^{2+}\right)$ to the cuprous ion $\left(\mathrm{Cu}^{+}\right)$and the second step is the simultaneous reduction of the cuprous

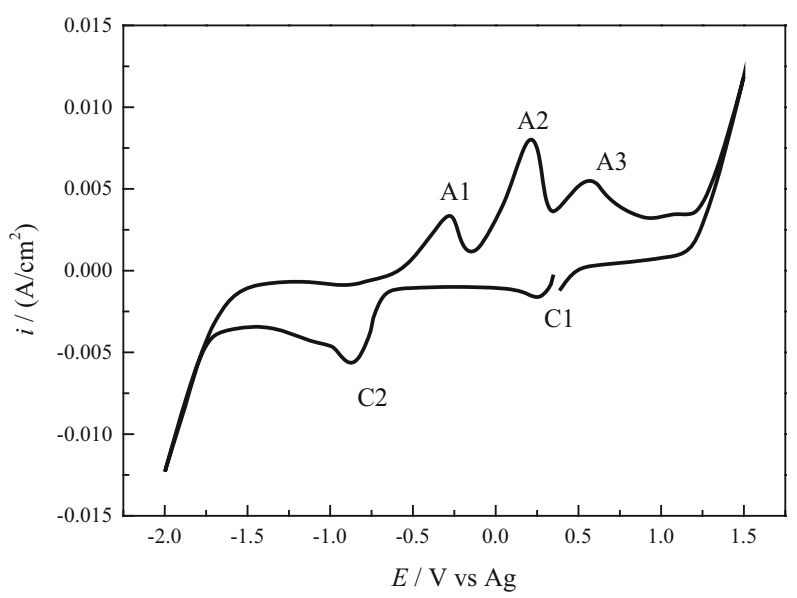

Figure 1. $\mathrm{CV}$ in $\mathrm{BMIC}-0.1 \mathrm{~mol}^{-1} \mathrm{CuCl}_{2} \cdot 2 \mathrm{H}_{2} \mathrm{O}-0.1 \mathrm{~mol} \mathrm{l}^{-1}$ $\mathrm{AgNO}_{3}$ on a $\mathrm{GC}$ electrode at $60^{\circ} \mathrm{C}$ with the sweep rate of 100 $\mathrm{mV} \mathrm{s}^{-1}$ from open current potential to negative and then positive.

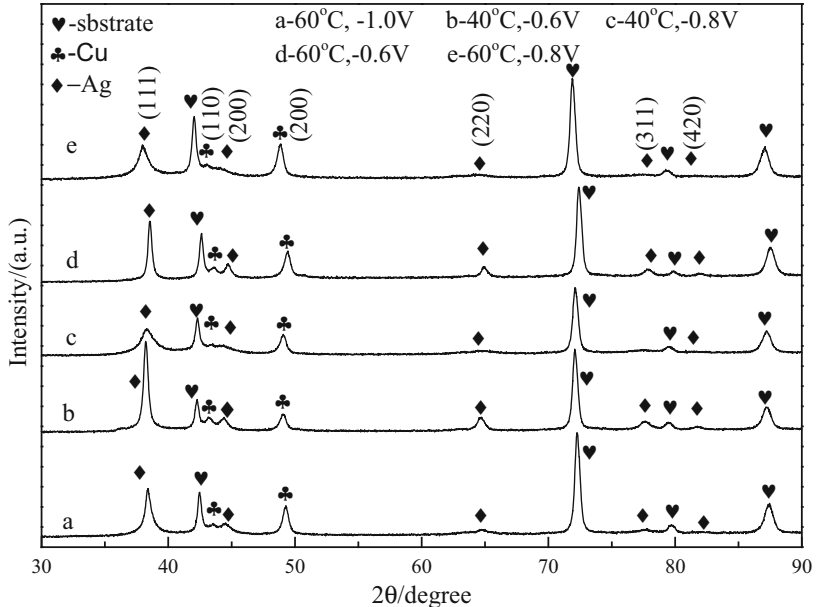

Figure 2. XRD spectra of electrodeposition layers under different electrodeposition conditions.

ion $\left(\mathrm{Cu}^{+}\right)$and the silver ion $\left(\mathrm{Ag}^{+}\right)$to form an alloy. There are three oxidation peaks labelled as A1, A2 and A3 in the oxidation curve. A1 corresponds to the oxidation of $\mathrm{Cu}^{0} / \mathrm{Cu}^{+}$, A2 corresponds to the oxidation peak of the copper-silver alloy and $\mathrm{A} 3$ corresponds to the oxidation peak of $\mathrm{Cu}^{+} / \mathrm{Cu}^{2+}$ $[11,15]$.

\subsection{Analysis of phase composition}

Figure 2 shows the XRD test results of electrodeposition coating under different deposition conditions. Comparing the standard cards PDF1-1164 and PDF1-1241, the XRD patterns of the electrodeposited copper-silver alloy under different deposition conditions are composed of the diffraction peaks of the brass substrate, copper and silver. Silver grows mainly along the five-crystal planes of (111), (200), (220), (311) and (420), and copper grows mainly along the (110) and (200) crystal planes. These results show that the co-deposition of copper-silver alloys is a separate metal copper phase and a single-metal silver phase rather than a copper-silver alloy phase, which is consistent with the results of Rajagopal et al [10].

\subsection{Analysis of micromorphology}

Figure 3 shows the micro-morphologies of copper-silver alloy electrodeposition coating under different conditions. It can be seen that when the temperature is $40^{\circ} \mathrm{C}$, as the deposition potential is increased from -0.60 to $-1.00 \mathrm{~V}$, dendritic, bract and granular coatings are sequentially formed. When the temperature is increased to $60^{\circ} \mathrm{C}$, there is also a similar trend of the microscopic morphology. However, at the same deposition potential, the coating particle size at a temperature of $60^{\circ} \mathrm{C}$ is always smaller than the particle size obtained at $40^{\circ} \mathrm{C}$. This result shows that an appropriate increase in temperature 


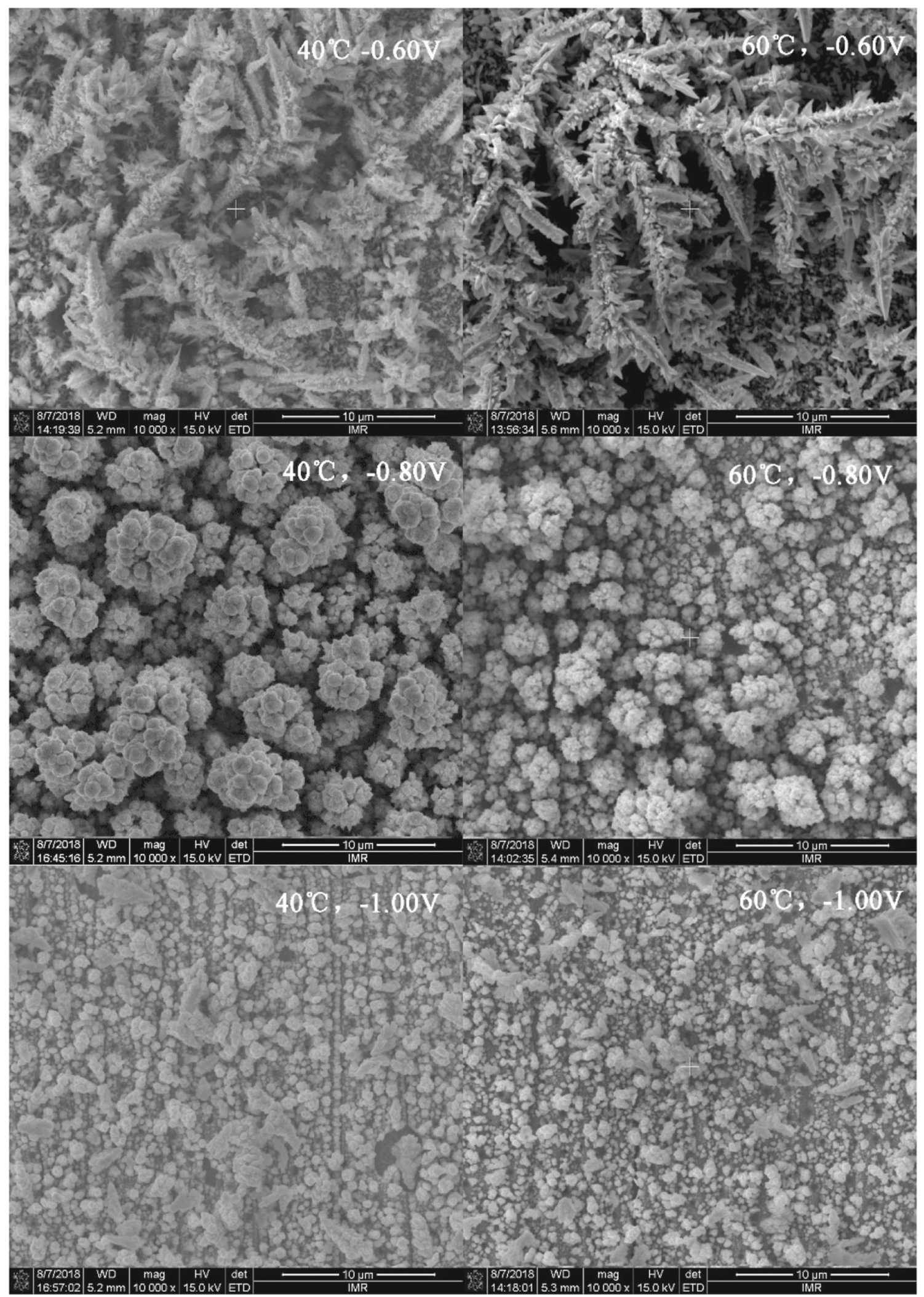

Figure 3. Micromorphology of copper-silver alloy electrodeposition under different conditions. 
and deposition potential contributes to a more uniform and fine coating.

\section{Conclusion}

Electrodeposition of a copper-silver alloy can be carried out in a BMIC ionic liquid. The reduction of the coppersilver ions in the ionic liquid needs to be first reduced to cuprous ions by copper ions, and then the cuprous ions and silver ions are simultaneously reduced to form a coppersilver alloy. Electrodeposition of copper-silver alloys under different conditions can obtain alloy coatings with different micromorphologies and different sizes. Properly increasing the deposition potential and temperature contributes to the preparation of better quality alloy coatings. The copper-silver alloy consists of copper and silver phases.

\section{References}

[1] Sun J, Ming T Y, Qian H X, Zhang M K and Tan Y 2018 Chem. J. Chinese Univ. 391497

[2] Ji S S, Yang P X, Zhang J Q, Lian Y, Zhang J and An M Z 2014 Mater. Lett. 13314
[3] Peter D V, Alicja S, Edward M, Jan F and Koen B 2013 Electrochim. Acta $\mathbf{1 0 8} 788$

[4] Rousse C, Beaufils S and Fricoreaux P 2013 Electrochim. Acta 107624

[5] Suneesh P V, Ramachandran T and Satheesh Babu T G 2018 Mater. Today: Proc. 516640

[6] Yang P X, Zhao Y B, Su C N, Yang K J, Yan B and An M Z 2013 Electrochim. Acta $\mathbf{8 8} 203$

[7] Chen P Y, Deng M J and Zhuang D X 2009 Electrochim. Acta 546935

[8] Debabrata P and Ramana G R 2014 Mater. Chem. Phys. 143 564

[9] Franz S, Barzi E, Turrioni D, Glionna L and Bestetti M 2015 Mater. Lett. 161613

[10] Rajagopal V, Velayutham D, Suryanarayanan V, Kathiresan M and Ho K C 2018 J. Taiwan Inst. Chem. Eng. 87 158

[11] Reyna-González J M, Reyes-López J C and Aguilar-Martínez M 2013 Electrochim. Acta 94344

[12] Barrado E, Rodriguez J A, Hernández P and Castrillejo Y 2016 J. Electroanal. Chem. $\mathbf{7 6 8} 89$

[13] Suryanto B H R, Gunawan C A, Lu X Y and Zhao C 2012 Electrochim. Acta $\mathbf{8 1} 98$

[14] Fu C P, Zhou H H, Peng W C, Chen J H and Kuang Y F 2008 Electrochem. Commun. 10806

[15] Ashraf B and Volkmar N 2015 Electrochem. Commun. 51 113 